\title{
Digital literacy practices among youth populations: A review of the literature \\ By Barbara Blummer
}

\begin{abstract}
Digital literacy includes a range of abilities from basic computing skills to the creation of multimodal texts. This literature review examines eleven articles that track the digital literacy practices of youth populations or individuals between the ages of 12 and 17. It describes the practices of these individuals through three perspectives, including: studies centered on general youth populations, research discussing innovative programs targeting students from low income families, and articles tracking digital literacy competencies among young immigrant learners. Foremost, the articles highlight young people's efforts to express themselves through their own online literacy. To this end it remains essential that educators correlate students' digital literacy habits in their personal lives to instructional practices in school.
\end{abstract}

\section{Introduction}

The definition of digital literacy includes a range of abilities from basic computing skills to the creation of multimodal texts. The New London Group suggests multimodal highlights meaning through the interconnection of linguistic, visual, audio, gestural and spatial elements. This literature review examines eleven articles that track the digital literacy practices of youth populations or individuals between the ages of 12 and 17. In 2007 the digital literacy competencies of these young people remain especially important as educators struggle to engage students as well as provide instruction relevant to their future academic and work environments. Jones (2007) maintained that college students view cell phones, instant messaging and the Internet as “extensions of themselves” (p. 207). The articles discussed below highlight young people's efforts to express themselves through their online literacies or skills that allow them to create textual content using a variety of technology tools. To this end, it remains essential that educators correlate students' digital literacy habits in their personal lives to instructional practices in school.

\section{Methodology}

The author queried numerous databases including Academic Search Premier, ERIC, ProQuest, Google Scholar, and Science Direct using the terms "digital, online, or multimodal literacy" with "youth, adolescents, teenagers, students, or young people." Bibliographies of relevant articles also served as a source of content for the review. The author highlighted material available in English and published within the last five years that focused on digital literacy practices among youth populations. The final sample of eleven articles was analyzed for common themes and these provided the structure for the review.

\section{Literature Review}

This literature review examines digital literacy from three perspectives including studies centered on general youth populations, research describing innovative programs targeting students from lowincome families, and articles tracking digital literacy competencies among young immigrant learners. Taken together these three approaches provide an illustration of digital literacy practices among youth worldwide.

\section{Digital literacy practices among youth}

The following research looks at general digital literacy practices among youth. These studies consisted of largely qualitative case studies sponsored by educational institutions between 2003 and 2007.
Ba, Tally, and Tsikalas (2002), authors of one of the articles in the review, offered one of the most comprehensive definitions of digital literacy. They described digital literacy as a "set of habits through which youngsters use information technologies for learning, work, and fun” (p. 3 (11)). According to the authors, these habits encompassed individuals' troubleshooting abilities, purposes for connecting, skills in using popular technology tools, as well as communication literacy, and web literacy.
Chandler-Olcott and Mahar (2003) focused on two adolescent girls' efforts to use information and communication technologies in their digital literacy practices outside of educational environments. According to the authors, the girls demonstrated their multiliteracies through their participation in online discussion groups as well as their creation of websites, fanfictions, and fan art, utilizing technology-mediated design. Data analysis occurred within a pedagogical framework, and included situated practice, overt instruction, critical framing, and transformed practice.

The organization of the results through these four components of a pedagogical framework illustrated the girls' opportunities within their communities of 
practice and especially the disconnect between the schools' instructional practices and the girls' need for support in their digital literacies. For example, Chandler-Olcott and Mahar described the mentorship and pedagogy of Rhiannon, one of the adolescent girls in the research study. They noted that the school failed to provide support for her in website design efforts. On the other hand, they reported both girls received overt instruction through online communities that also provided them opportunities for mentorship as well as richer social lives. According to the authors, the girls' "online communities of practice" offered them "certain kinds of acceptance and friendships" (p. 379). Still, Chandler-Olcott and Mahar insisted the girls' WebTV and mailing list activities did not interfere with their face to face relationships but rather increased their own sense of identity especially as "designers and as users of technological tools” (p. 380).

The article listed several implications of the research results. Foremost, Chandler-Olcott and Mahar maintained literacy teachers should provide opportunities for multimedia composition that supported students' interests. To this end, the authors indicated "classrooms that embed such tool use within social learning communities" may increase students' interest in school curricula (p. 381). According to the article, activities that allow students to construct online texts in classrooms and receive feedback from teachers and peers facilitate a potential shift toward a "learnercentered paradigm” (p. 381). The authors especially highlight the role of multimedia and multimodal technology in offering opportunities for students to serve as mentors as well as benefit from mentorship. In addition, they suggested teachers could help link students' interests to the appropriate online communities as well as offer feedback and critique. Lastly, the researchers supported larger scale research on adolescents' technology mediated literacy practices with variation in participants regarding ethnic, race and language categories.

Eshet-Alkali and Amichai-Hamburger (2004) compared digital literacy competencies among different age groups utilizing a terminology framework that included five competencies. They described photovisual literacy as the ability to read instructions from graphic interfaces, reproduction literacy as the creation of new products through digital texts, branching literacy as the construction of knowledge from nonlineal hyper-textual navigation, information literacy as the ability to assess the quality of information retrieved, and social-emotional literacy as the possessing online communication skills.
Their research focused on competencies of twenty high school students with an average age of 16.9 years in comparison with twenty adults and twenty college students. Participants completed computer-based assignments that measured their skill in the five digital competencies. The results highlighted the photo-visual and branching literacy abilities of the high school and college students compared to other study participants. However, the authors noted youth performed poorly with information and reproductive literacy tasks.

In conclusion, Eshet-Alkali and Amichai-Hamburger suggested digital literacy skills vary among age groups. The authors maintained the young people's performance with photo-visual literacy suggest their advanced skills in utilizing user interfaces and interpreting graphical displays. On the other hand, the article indicated the low level of text reproductive literacy efforts among young participants underscored the need for instruction in cognitive rather than technical digital skills. Likewise the researchers argued the youth's poor performance on tasks measuring information literacy highlighted the availability of programs that enhance students' "critical thinking and promote information literacy” (p. 426). According to the authors, the students' lack of information literacy skills illustrated their "weakness as educated consumers of information" and potential for being "easily manipulated” (p. 426). Lastly, Eshet-Alkali and Amichai-Hamburger advocated additional research on socio-emotional literacy skills due to the newness of this "rapidly-evolving” concept (p. 427).

Lewis and Fabos (2005) examined the impact of Instant Messaging (IM) on the social identities of seven youth ranging in age between 14 and 17 years old. The researchers selected participants with home Internet access and who were "avid and dexterous IM users” (p. 477). The methodology of the study centered on qualitative interviews that included three categories of questions on instant messaging such as: general appeal and procedural matters, peer and parent issues, and style or word choice.

An analysis of the data illustrated the students' abilities to use language in complex ways. The youth paid careful attention to word choice and spelling and also interweaved multiple messages within the context of larger stories. In addition, Lewis and Fabos discovered instant messaging reflected young people's social networks revealing personal status and connections with others. The researchers also described the youths' abilities to manipulate the surveillance features of instant messaging to weld power as well as change 
identities in their online communications. Lastly they emphasized the performative and multi-voiced characteristic of instant messaging that facilitated the creation of "versions of ones self" for multiple audiences simultaneously (p. 493).

In their discussion Lewis and Fabos maintained the study's outcome contained implications for formal literacy instruction. First, the authors argued the participants' skills with the "digitally mediated form of reading and writing" supported instruction in other forms of literacy such as the "deliberative reading and writing practices that are basic to certain kinds of analysis and critique” (p. 496). Second, Lewis and Fabos urged educators to focus on applying youths' outside literacy practices within school settings. To this end, the researchers advised querying students to identify features of their out-of-school digital literacies (including chat, IM, fanfiction, gaming) that remained appealing and how "they differ from school literacies" (p. 496). According to the authors, these discussions could highlight the importance of audience and aptitudes for different types of writing. Third, Lewis and Fabos noted the instant messaging interactions they observed did not illustrate complex writing and therefore they promoted teaching students to read analytic online materials that required "lateral reading across genres and modes” (p. 497). In addition, the authors supported the availability of student activities such as blogs that fostered the utilization of multimodal design to discuss "complex topics" (p. 497). Lastly, the article promoted continued studies on instant message usage among youth targeting a diverse group of participants from various ethnic and socioeconomic backgrounds.

Bulfin and North (2007) reported on an ethnographic case study of digital literacy practices among 15 and 16 year olds in secondary schools in Melbourne, Australia. The research goal sought to explore young people's use of Information and Communication Technologies (ICT) in their everyday lives and especially the connections and disconnections between learners' literacy practices inside and outside of school. The data, including interviews, student media diaries, and observational notes, highlighted the importance of technology in the daily lives of these youth.
The article's theme centered on student efforts to access cell phones, iPods, computer games and the Internet for gaming, instant messaging, and blogging during school hours. According to Bulfin and North, this represented the "concept of negotiated practice" where young people negotiate literary practices across different spaces in relation to their use of ICT (p. 248). The article described students circumventing blocked websites, sneaking games into computer hard drives, and utilizing cell phones and iPods within the school environment.

Bulfin and North argued the study illustrated the youths' negotiating practices as they travel through various spaces. These practices, the authors believed, underscored the need for educators to consider young people's perspectives in developing English and literacy curriculums in secondary schools. Moreover Bulfin and North suggested the study results highlighted the value of teaching students competencies in authoring as well as communication tools and technologies. They pointed out schools could instruct students on how to use a "range of forms and modes" for communicating (p. 260). According to Bulfin and North, teaching these abilities can also help educators illustrate to students the impact of these technologies and texts on their lives thereby assisting them in "negotiating various literacy practices" (p. 260). In addition, the article maintained the availabilities of new technologies blur the distinctions of home, school, community, online and offline requiring a reassessment of the relationships among these concepts. Lastly, the authors urged educators to consider the problems of power and ideology associated with "literacy, technology and schooling"

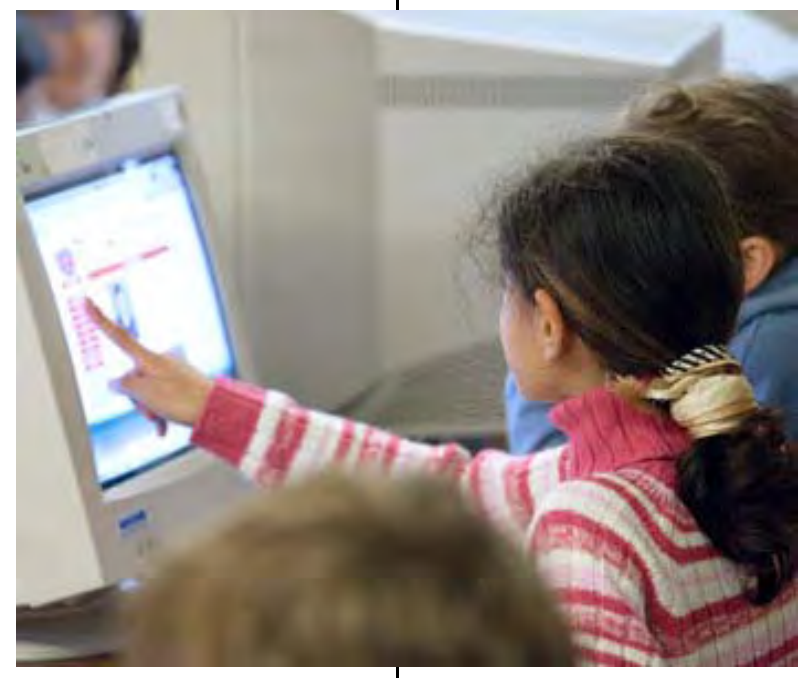
(p. 261).

Several consistent themes appeared in the articles describing general digital literacy practices of youth. First, many of the articles noted the importance of technology to these teens. Second, the authors depicted these youth as especially savvy in utilizing various digital literacies. On the other hand, several of the articles described the need for school programs to modify instructional practices to consider students' online literacies competencies as well as their literacy interests. These practices focused on teaching 
analytical reading and writing using popular technologies in the context of student interests. Ultimately adopting these changes in the curriculum allow schools to remain relevant to students' current and future literary practices.

\section{Innovative Digital Literacy Programs for Students in Low Income Families}

The following group of articles, published between 2002 and 2007, evaluated innovative digital literacy programs for students from low income families. Two of these studies were centered in California, another research project described a high school's efforts to incorporate multiple literacy instruction in their curriculum, and the last inquiry evaluated digital literacy competencies in a low income Mexican region. Ba, Tally, and Tsikalas (2002) compared the digital literacy practices of middle school students from low and middle income households. The authors sought to illustrate the emerging digital literacy for both youth populations. The study was linked to a program that provided a home computer, training, technical support, and Internet access to low income families in California. The researchers analyzed the data based on five components of digital literacy including: purposes of computing, troubleshooting, fluency with common applications, communications literacy, and web literacy.

Foremost, the findings highlighted the importance of the computer among children from low income families for "completing and enhancing their schoolwork" (p. 24). On the other hand, the researchers found middle-income students' primary computer activities included communicating with friends and recreational purposes. In summarizing, the authors identified three factors affecting children's digital literacies. First, they listed the technological environment, or the length of availability of home computers and the presence of money for stable Internet connectivity. Second, was the social environment and this included parental and peer attitudes as well as computer expertise. The final factor centered on the school and especially, homework assignments, the amount of computer instruction and school hours.

According to the report, the study results supported the availability of programs that provided low income families with home computers as well as computer training. In their conclusion, Ba, Tally, and Tsikalas stressed the findings "demonstrated that home computers help children develop digital literacy" (p. 55). To this end, they recommended providing all students and teachers in a school with home computers. The researchers also noted the importance of instructing parents as well as children in computer literacy and offering troubleshooting strategies. In addition, the report highlighted the need to educate schools on their roles in facilitating children's computing. Lastly, the authors advocated further research on the relationship among family income, social capital, and technology.

Ware and Warschauer (2005) traced digital literacy uses among students in two technology-intensive learning spaces over a two year period. The authors aimed to reveal the emerging literacies for this population. In the Digital Underground Storytelling for Youth (DUSTY), a university-community partnership providing after school programs for youth, students created hybrid texts or digital stories utilizing a combination of traditional text as well as multimodal products such as speech, writing, image, gesture, and music. According to the authors, young people received mentoring from college students in a structured media-intensive environment that allowed the learners to build different identities without the "testing and curricular imperatives of school” (p. 435).

In their analysis, the authors illustrated the use of multimodal texts for "engaging with active exploration, self-representation, and reflection" as well as for academic learning (p. 436). Moreover, they argued the digital stories improved students' educational identities. They reported on two individuals who gained reading and writing skills through their multimodal practices. Lastly, the study's results highlighted the disconnection between the academic literacy that students encountered in schools and the new media.

In their summary, Ware and Warschauser characterized after-school collaborations that focused on new media and new literacies as containing challenges characteristic of "alternative learning spaces" (p. 443). They reiterated Hull's (2003) concern that educators in these environments balance the use of technology tools to avoid efforts that "domesticate youth culture" (p. 233). Moreover, the authors pointed out, hybrid literacies remain difficult to evaluate through conventional testing and may not improve the quality of students' work. Still, Ware and Warschauser suggested hybrid texts can serve as a construct to connect students to academic literacy due to the flexible nature of the format that can adapt to the content. They maintained that the challenge for educators centers on balancing literacy and 
communicative practices of youth culture with curricular requirements. However, they stressed that teachers still had great potential to serve as innovators "in the world of media and new literacy" (p. 444).

Tierney, Bond, and Bresler's (2006) inquiry centered on a ten year in-depth study of high school students' use of multimodal literacy tools during their secondary education. In the study students received access to cutting edge multimedia technologies to explore "images, soundtracks, and text interconnected in very complex, multifaceted ways" (p. 361). According to the article, the researchers' evaluations focused on the process students utilized to explore topics, the multimodal nature of the genres, as well as the individual's view of themselves as learners.

Tierney, Bond, and Bresler concluded the presence of the media prompted a greater use of multiple resources and an in depth examination of topics. They pointed out students became more willing to experiment with ideas such as multi-layering and graphic interfaces and often worked collaboratively. In addition, the authors described the increased skills and roles of the students that allowed them to "represent the complex interrelationship between ideas more easily" (p. 364). Lastly, they noted all of the students in the program sought a college education following high school and many eventually enrolled in graduate schools.

In their conclusion, the authors asserted digital literacies in collaborative learning contexts contain attributes that distinguish them from traditional school based literacies. The article highlighted this information in a table listing the differences between traditional print-based school literacies and the new multiple literacies. Foremost, Tierney, Bond, and Bresler claimed the findings demonstrated students' opportunities with the multiple literacies offered them "new texts, new ways of negotiating meaning, and new ways of knowing" (p. 366). According to the authors, these literacies contained the potential to impact the social, political, and economic lives of individuals. Still, Tierney, Bond, and Bresler feared teachers' pedagogical focus would center on students learning of the technologies rather than students using a range of multimodal literacy tools. In addition, they also admitted the benefits of multiple literacies remains difficult to test and promoted authentic assessments that illustrate the benefits of "collaborative and inquiry based work" (p. 366).

Huerta and Sandoval-Almazan (2007) reported on digital literacy skills among Mexican telecenter users in poor counties. The research included a case study that evaluated participants through Eshet-Alkai's (2004) digital literacy framework. This definition contained five skills including: photovisual, reproduction, branching, information, and socioemotional. The data included interviews with 31 telecenter users, 31 telecenter operators, and focus group participants. All of these individuals represented students that lived in areas with high levels of poverty. Nearly three fourths of the participants ranged in age between 10 and 17 years old. The data collected from the focus groups aimed to expand on telecenter users difficulties with information retrieval.

Foremost, Huerta and Sandoval-Almazan illustrated the popularity of telecenters for email, to search for information, and for online games. However, the authors reported participants typically failed to utilize computers for chatting, an activity Huerta and Sandoval-Almazan said telecenter operators or guides attempted to discourage. Still, the researchers emphasized the importance of the activity to users especially for building "social capital" that can "foster economic development” (p. 226).

The authors concluded that the lack of digital literacy skills among study participants, especially in branching, recreation, and information skills, affected their Internet experience. For example, interviews revealed users required assistance in selecting browsers as well as finding relevant material and synthesizing and analyzing information. To this end, Huerta and Sandoval-Almazan proposed providing training for telecenter users in the "functionality of the hardware and software" as well as creating online tutorials for information literacy instruction (p. 227). In addition, they suggested the installation of automated translators to address language differences. The article also maintained telecenter centers could offer services to illiterate individuals if operators adopted an intermediary role in providing access to Internet programs geared for these populations. Lastly, the researchers argued for increased attention to telecenter Internet technical problems, such as slow speed and connectivity issues. In their conclusion, Huerta and 
Sandoval-Almazan asserted the exploratory nature of the research limited its ability to be "generalized to other populations" (p. 229). Still, they pointed to the need for future inquiries to determine if the study's participants' literacy practices differed from their counterparts in similar areas.

These studies highlighted the numerous benefits underprivileged youth receive from programs that promote digital literacies. In addition to the computer skills students acquire through these programs, the articles also document opportunities for revealing creativity and self-expression. To facilitate the programs' successes the authors' emphasized the need for supportive personnel for troubleshooting and direction.

\section{Examining digital literacy practices among immigrant students}

The final group of articles focused on digital literacy practices among immigrant students. Published between 2004 and 2007, these studies tracked the importance of digital literacies among young peoples from various ethnic groups for social relationships as well as self-expression. Two of the studies were centered in the New York and the other in an Arabic community in Australia.

Cruickshank (2004) studied the literacy practices of four teenagers and their families in Arabic speaking suburbs in Australia. He focused on the teenagers' writing and reading habits outside of school to illustrate their home literacy practices. Data from the qualitative study included interviews, field notes, literary diaries, documents and artifacts. The research remained part of a larger study conducted on Arabicspeaking community and local secondary schools between 1994 and 2000 .

According to the data analysis, the amount of reading and writing children did outside of school was "quite extensive" despite their teachers' tendency to label these students as "non-readers" (p. 463). Foremost the literacy and communication practices of the children as well as their parents changed with the availability of new technologies. Cruickshank maintained the presence of a computer in all of the households by 1999 produced a change in technology from visual to text especially through the Internet and chat. The author suggested this shift facilitated the development of a different range of "writing, reading, and perceptual skills" among the youth (p. 466). In addition, the article traced the impact of mobile phones on increasing the children's expertise in instant messaging.

In conclusion, Cruickshank highlighted the influence of the families' adoption of technology mediated communication in the four-year period on children's literacy practices. Foremost, he described the teenagers' literacy practices as "more dynamic and complex than recognized” (p. 470). Lastly, he blamed the teachers' perception of these children as nonreaders to educators' difficulties in defining the construction, understanding, and interpretation of home and school literary practices. This misunderstanding, he argued, limited the ability of the school literacy program "to change and adapt” (p. 471). To this end, Cruickshank emphasized the need to understand the teenagers as well as their schools' literacy practices.

Walsh (2007) reported on students multimodal literacy efforts between 2002 and 2003 within a small school in New York City's Chinatown. The author, a teacher at the school, described the results of his efforts to incorporate students' out of school digital technologies practice into the classroom. His study encompassed fifty-eight 12 and 13 year-old first and second generation Chinese students. He required these students to design websites that represented online tutorials and included individual as well as collaborative efforts. The author described students' designs as illustrating "co-deployment of resources from language and other semiotic systems” (p. 79).

According to Walsh, the websites represented a hybrid form that recombined semiotic modes, or sign and symbol interpretations, in different ways that demonstrated a superior organizational design. He described one student's website titled "Life in the Dust Bowl Panhandle Region” as providing viewers with an audio ballad and then simultaneously displayed a poem on the topic transposed on an image of Route 66 . Walsh referred to the project as a "linguistic, visual, and audio hybrid medium" and pointed out users could access additional information on the topic through page links (p. 82).

In his conclusion, Walsh noted his perception of the students as multimodal designers facilitated his understanding of multimodality and incorporate the use of digital culture texts in his teaching. Foremost he 
emphasized his role in encouraging students to utilize their digital literacy skills in the classroom. According to Walsh, this facilitated a shift in the focus of literacy instruction "from students imitating modeled literacy practices" to students as innovators of "new genres" (p. 84). He suggested that allowing students to use out of school literacy practices within the context of school subjects improved their understanding of the topic and especially the final output. Lastly, he reiterated the importance of making school based literacy practices “relevant to the students' life worlds" (p. 84).

McGinnis (2007), et al., tracked three transnational youth in their use of multimodal textual practices to create online identities. The authors also explored their efforts to cultivate social relations and create transnational communities of practice through their online literacy practices. Digital literacy for these youth remained multimodal or included the integration of words with visual images, sound, streamed video, hybrid language, and "multilingual words" (p. 6).

The research centered on the personal web pages and blogs of three high school students in suburban communities of New York City. In their analysis, the researchers considered modes, meaning making, and messages of the youths' blogs and MySpace accounts. Foremost, their analysis considered how the data remained symbolic of the youth in articulating and performing multiple identifications.

In their conclusion, McGinnis, et al., argued the digital literacy practices of the adolescents offered them opportunities to express explore and describe their multiple identifications. Moreover, the article suggested the students' online spaces illustrated their attempt to "express, explore, and describe their multiple identities" as well as "contest and challenge their position as youth living in transnational context" (p. 18). According to the authors, the youth "created new multimodal textual forms" by combining various resources with results that offered "new meanings" (p. 19). McGinnis et al., suggested the studies highlight the diverse aspects of these teenagers lives and the ability of their digital literacies to provide them flexibility in "topic, modes, medium," and audience for communicating (p. 20). The authors challenged educators to understand the students' literacy practices especially how they "express themselves through multilingual language forms” (p. 20).

Like their underprivileged counterparts, the online literacy habits of the immigrant youth served as an outlet for expression as well as for garnering support from like-minded individuals. Moreover, as the research by Walsh as well as McGinnis et al., suggested, the creation of multimodal texts remained especially significant in fostering self-identity, creativity as well as collaboration among youth. These benefits were also noted by Chandler-Olcott and Mahar in their research of young girls' literacy practices. Finally, these studies also supported efforts to make literacy practices in educational program instruction relevant to students' life outside of school.

\section{Implications}

Alvermann (2004) reiterated the concept of literacy "reinventing itself through hypermedia and digital technologies" and suggested this contained "enormous implications for teachers at the middle and high school level” (p. 78). The articles discussed above illustrated the reinvention of literacy as well as the benefits students received from programs that recognize and validate their multiliteracies. Foremost, these studies support the creation of educational opportunities highlighting students authoring and communication skills in using the new media. Several authors encouraged instructors to develop activities that challenged and enhanced students' online literacy skills such as exposing them to complex reading or allowing learners to create blogs as class assignments. In addition, Huerta and Sandoval-Almazan as well as Eshet-Alkali and Amichai-Hamburger defined digital literacy as including information literacy and their findings illustrated the need for its instruction to youth populations. The articles also noted the importance of recognizing students' interests in developing projects that capitalized on learners' multiple literacies.

Although the small sample of articles discussed in this review yielded similar themes and outcomes, additional research is required to reveal the applicability of these findings to other youth populations. This remains especially true for the selfreported teacher classroom inquiries. Another shortcoming of the studies centered on the qualitative focus of the methodology. Inquiries that consider a mixed method approach for evaluating digital literacy practices among youth may foster different outcomes. Likewise, additional studies that examine specific youth populations or their digital literacy practices within various virtual environments such as Facebook, MySpace, and Second Life would also add to the literature on this topic.

\section{Conclusion}

The topic of digital literacy is characterized by a nebulous definition and limited research studies that are often centered in foreign countries. However, the 
rising importance of digital technologies to youth populations underscores the need for an understanding of their multiple literacies. The recent focus on information, communication, and technology (ICT) skills as illustrated by the Information Technology Literacy project of the Educational Testing Service (ETS) may foster attention on digital literacy. In 2006 ETS released a web-based interactive tool for evaluating high school and college students' proficiencies in utilizing technologies such as e-mail, web browsers, and library databases to "solve information-related tasks” (Brasley 2006, p. 44). This test, while revealing student digital competencies, also challenges assumptions about evaluating multiliteracies and especially the role of educators in promoting literacy instruction based on students' use of technologies.

\section{References}

Alvermann, D. E. (2007). Media, information communication technologies, and youth literacies: A cultural studies perspective. American Behavioral Scientist, 48(1), 78-83.

Ba, H., Tally, B., \& Tsikalas, K. (2002). Children's emerging digital literacies: Investigating home computing in low- and middle-income families. (Report No. IR021996). East Lansing, MI: National Center for Research on Teacher Learning. (ERIC Document Reproduction Service No. ED477716).

Brasley, S. S. (2006). Building and using a tool to access info and tech literacy. Computers in Libraries, 26(5), 6-48.

Bulfin S., \& North, S. (2007). Negotiating digital literacy practices across school and home: Case studies of young people in Australia. Language and Education 21(3), 247-263.

Chandler-Olcott, K., \& Mahar, D. (2003). Tech-savviness meets multiliteracies: Exploring adolescent girls' technology mediated literacy practices. Reading Research Quarterly, 38(3), 356-385.

Cruickshank, K. (2004). Literacy in multilingual contexts: change in teenagers reading and writing. Language and Education, 18(6), 459-473.

Eshet-Alkali, Y., \& Amichai-Hamburger, Y. (2004). Experiments in digital literacy. CyberPsychology \& Behavior 7(4): 421-429.

Gilster, P. (2000). Digital literacy. In The Jossey-Bass reader on technology and learning (pp. 215-225). San Francisco, CA: John Wiley \& Sons.

Huerta, E. \& Sandoval-Almazan, R. (2007). Digital literacy: Problems faced by telecenter users in Mexico. Information Technology for Development 13(3): 217-232.

Hull, G. (2003). AT LAST: Youth culture and digital media: New literacies for new times. Research in the Teaching of English, 38(2), 229-233.
Jones, D. C. (2007). Thinking critically about digital literacy: A learning sequence on pens, pages, and pixels. Pedagogy 7(2), 207-221.

Lewis, C., \& Fabos, B. (2005). Instant messaging, literacies, and social identities. Reading Research Quarterly 40(4):470-501.

McGinnis T. et al. (2007). "indianpride”: online spaces of transnational youth as sites of creative and sophisticated literacy and identity work. Linguistics and Education, 1-22.

Pew Internet \& American Life Project (2007). Teens and Social Media. http://www.pewinternet.org/pdfs/PIP_Teens_Social _Media_Final.pdf

Pool, C. R. (1997). A new digital literacy: a conversation with Paul Gilster. Educational Leadership,

Tierney, R. J., Bond, E, \& Bresler, J. (2006). Examining literate lives as students engage with multiple literacies. Theory into Practice, 45(4), 359-367.

Walsh, C. (2007). Creativity as capital in the literacy classroom: Youth as multimodal designers. Literacy, 41(2), 79-85.

Ware, P. D., \& Warschauer, M. (2005). Hybrid literacy texts and practices in technology-intensive environments. International Journal of Educational Research, 43(7-8), 432-445.

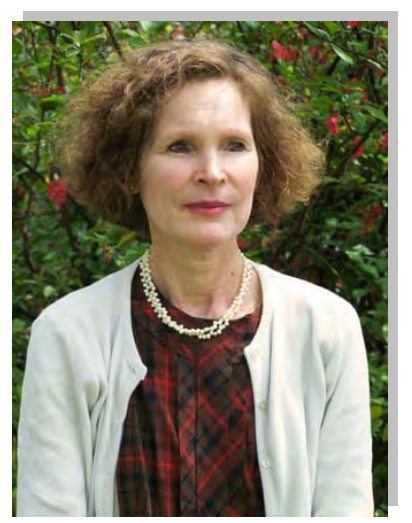

Barbara Blummer is the reference librarian for the Center for Computing Sciences, a federally funded research and development center located in Bowie, Maryland. She has been working in special libraries since 1992. Ms. Blummer is also a doctoral student in instructional technology at Towson University. She is a member of the American Library Association as well as the American Society for Information Science and Technology. Her research interests center on information and digital literacies.

bablumm@super.org 